\title{
Para além da Sala de Aula: Uma Experiência de Ensino-Aprendizagem na Graduação em Relações Públicas ${ }^{1}$
}

\author{
Ana Cristina da Costa Piletti Grohs** e Maria Aparecida Ferrari ${ }^{+}$ \\ -Doutoranda do Programa de Ciências da Comunicação pela Escola de Comunicações e Artes da \\ Universidade de São Paulo (ECA/USP), Aluna do Programa de Aperfeiçoamento do Ensino (PAE/ USP), \\ Bolsista convênio Fapesp/Capes (Processo n. 2014/26010-5). \\ 'Livre-docente e professora na pós-graduação e na graduação do Departamento de Relações Públicas, \\ Propaganda e Turismo da Escola de Comunicações e Artes da Universidade de São Paulo (ECA/USP)
}

*Autoras para correspondência: anacris.piletti@usp.br, maferrar@usp.br

\section{RESUMO}

Proporcionar experiências educacionais que valorizem o protagonismo do estudante e integrem teoria e prática tem sido uma das principais dificuldades para os professores da educação superior e dos cursos de Relações Públicas no Brasil. Neste relato, é apresentado o projeto Conexão, desenvolvido na disciplina Teoria e História das Relações Públicas, com o objetivo de engajar os estudantes no processo de aprendizagem e dinamizar os significados dos conceitos estudados no decorrer do semestre. Como resultados, verificou-se a preferência pelas estratégias educacionais ativas, assim como o potencial motivador de projetos que incentivem os estudantes a interagirem e a produzirem estudos que extrapolem a sala de aula. $\mathrm{O}$ projeto é um exemplo de atividade didática que integra teoria e prática e pode contribuir para a reflexão de docentes e gestores de cursos preocupados com a melhoria dos processos educativos.

Palavras-Chave: Relações Públicas; Ensino-Aprendizagem; Teoria e Prática.

\begin{abstract}
Providing educational experiences that value the protagonism of the student and integrate theory and practice has been one of the main difficulties for teachers of higher education and Public Relations courses in Brazil. This report presents the Connection Project, developed in the discipline Theory and History of Public Relations with the aim of engaging students in the learning process and dynamizing the meanings of the concepts studied during the semester. As results, the preference for active educational strategies was verified, as well as the potential motivator of projects that encourage the students to interact and to produce studies that extrapolate the classroom. The project is an example of didactic activity that integrates theory and practice and can contribute to the reflection of teachers and managers of courses concerned with the improvement of educational processes.
\end{abstract}

Keywords: Public Relations; Teaching-Learning; Theory and Practice.

\section{Introdução}

A existência de uma cultura que valorize o trabalho docente na graduação ainda é algo pouco comum nos cursos universitários brasileiros. Planejar os cursos de forma sistêmica e integrada, conhecer o repertório dos estudantes, desenvolver habilidades e atitudes de pesquisa e incentivar a participação ativa foram necessidades identificadas por Bordenave e Pereira (1983) e, mais recentemente, por Almeida e Pimenta (2011).
Nos cursos de graduação em Relações Públicas, a realidade não é diferente. Já nas décadas de $80 \mathrm{e}$ 90, Andrade (1986) e Braga (1992) demonstravam preocupações em relação à formação do corpo docente e à desarticulação entre a formação teórica e a prática nos cursos. Conduzido por Ferrari (2017), um estudo nacional, com 255 professores e 53 coordenadores dos 66 cursos em funcionamento no Brasil, revelou que a aula expositiva ainda é a estratégia educacional mais conhecida e utilizada 
pelos docentes. Além disso, eles reconheceram que lhes faltam conhecimentos para desenvolver novas metodologias educacionais. Entre os coordenadores, diante do excesso de atividades burocráticas, verificou-se ainda a dificuldade em focalizar no trabalho pedagógico junto aos professores.

Quanto aos estudantes, Knowles (1970) destacou que os adultos respondem menos prontamente a fatores externos para a aprendizagem (como as notas) do que a fatores internos (como a autorrealização). Para Brophy (1987), os estudantes são mais propensos a querer aprender quando eles apreciam o valor das atividades e quando acreditam que terão sucesso se aplicarem os esforços necessários. Segundo Lebrun (2002), as estratégias educacionais ativas são mais propícias para envolver os estudantes no processo de aprendizagem. No desenvolvimento de atividades didáticas, sugere que sejam observados os cinco componentes descritos no Quadro 1.

No Quadro 1, observa-se que a aprendizagem é um processo ativo de construção de conhecimentos a partir das relações que o sujeito estabelece com as informações, as pessoas e as situações que o cercam. O ensino consiste na mediação e disponibilização

\section{Motivar (-se)}

Depende do contexto geral, da tarefa e do meio didático

Informar (-se)

Depende das informações e de diferentes apoios

\section{Ativar (-se)}

Depende de competências de nível superior (análise, síntese, avaliação, crítica)

\section{Interagir}

Depende da interação com os diversos recursos e pessoas

\section{Produzir}

Depende da construção pessoal ou da produção de novos conhecimentos de ocasiões para que o sujeito possa aprender. Assim, o ensino-aprendizagem é um processo interativo e contextual que deve considerar as diferentes formas de aprender dos estudantes.

A partir de estudos realizados por Marton e Säljö (1976), na Suécia, Biggs (1999) apresentou duas principais abordagens em relação aos hábitos acadêmicos dos estudantes. De um lado, o estudante não acadêmico. Prioriza a memorização dos conteúdos, estuda para conseguir passar na prova e não atribui significado àquilo que é ensinado. Esse tipo de aprendizagem é reforçado quando o professor foca somente no conteúdo e não estimula a reflexão. Do outro lado, o estudante acadêmico. Questiona e busca respostas a suas indagações. Demonstra necessidade de encontrar significado para o conteúdo aprendido e verificar como este pode ser aplicado. Nesse caso, o professor busca provocar respostas, questionando e apresentando problemas.

Enquanto o estudante acadêmico apresenta alto nível de engajamento nas atividades de aprendizagem, constou que, nos cursos de Relações Públicas, 84\% dos 255 docentes ainda percebem os estudantes como não acadêmicos (FERRARI,

Fornecer meios para que o estudante possa atribuir valor à tarefa, ressaltando elementos que tenham significado e sentido para ele.

Integrar as partes recolhendo a partir do contexto informações em campos de natureza variada.

Manipular e relacionar as várias formas de representações, tratar corretamente a informação, colocar questões, fazer emergir e resolver problemas.

Ação sem feedback é improdutiva para o estudante, valorizar fatores relativos à comunicação e ao trabalho em equipe.

Importância da produção pessoal, da atividade de criação e do papel da (auto)avaliação.

Quadro 1 - Componentes do processo de aprendizagem. Fonte: Baseado em Lebrun, 2002. 
2017). Assim, para que possam alcançar os mesmos níveis de compreensão que seus colegas mais engajados, eles precisam de mais ajuda dos professores. E, segundo Biggs (1999), o ensino baseado em estratégias ativas reduz significativamente a diferença no nível de engajamento e na atividade cognitiva desses dois perfis de estudantes.

Nesse contexto, foi desenvolvido o projeto $\mathrm{Co}^{-}$ nexão na disciplina Teoria e História das Relações Públicas do curso de graduação de Relações Públicas na Escola de Comunicações e Artes, Universidade de São Paulo (ECA/USP). O objetivo do projeto foi engajar os estudantes no processo de aprendizagem e dinamizar os significados dos conceitos estudados no decorrer do semestre. A partir dos componentes de aprendizagem propostos por Lebrun (2002), apresentaremos a seguir a estrutura geral do projeto Conexão e alguns dos resultados de sua aplicação com turmas que participaram da atividade nos anos de 2013 e 2014.

\section{Desenvolvimento}

A disciplina Teoria e História das Relações Públicas é oferecida no primeiro semestre do curso de Relações Públicas da ECA/USP, nos períodos matutino e noturno, e tem caráter introdutório e teórico. É o primeiro contato dos estudantes ingressantes com conceitos da área profissional de Relações Públicas. Logo, o projeto Conexão constituiu uma experiência de aprendizagem na qual o aluno foi desafiado a relacionar os conteúdos estudados com as práticas organizacionais e do mercado comunicacional.

Entre os objetivos educacionais do projeto, destaca-se o de levar o estudante a conhecer a estrutura e as práticas de um departamento de comunicação de uma organização real analisando-o à luz das teorias das Relações Públicas. O trabalho foi produzido em grupos que receberam orientações periódicas a partir de um roteiro estruturado em quatro etapas principais: 1) perfil da empresa; 2) análise dos públicos; 3) planejamento e instrumentos de comunicação; e 4) análise dos modelos e práticas de Relações Públicas.

Ao final do projeto, os grupos foram convida- dos a compartilhar os resultados e, em conjunto com a docente e a monitora do Programa de Aperfeiçoamento de Ensino (PAE), compilararam os resultados encontrados em um único relatório a ser apresentado em um congresso da área. Com o intuito de entender os efeitos educacionais do uso de tal estratégia, no Quadro 2, associaram-se as atividades realizadas pelos estudantes para a produção do projeto com os componentes do processo de aprendizagem descritos por Lebrun (2002):

Do Quadro 2, pode-se afirmar que o projeto Conexão demandou prontidão do estudante para se dedicar a atividades de pesquisa teórica e empírica, tais como leitura e compreensão de textos e realização de entrevistas. Uma matriz conceitual que permitiu relacionar os dados coletados nas entrevistas com as teorias estudadas foi criada com o objetivo de auxiliar os estudantes na análise e interpretação dos resultados, assim como de compilar os dados coletados por todos os grupos.

Desde o início do projeto, os estudantes foram informados de que as pesquisas seriam analisadas conjuntamente para compor um produto final a ser apresentado em um congresso, o que contribuiu positivamente para o envolvimento no trabalho. Nos anos de 2013 e 2014, eles apresentaram os resultados do projeto, respectivamente, no $I X$ Foro Internacional de Relaciones Públicas/ VI Encuentro Interamericano de Profesores de Relaciones Públicas, em Montevideo, Uruguai, e no XIV Congresso Internacional de Relações Públicas e Comunicaşão, em Salvador, Brasil.

Alguns depoimentos revelaram o potencial do projeto para engajar os estudantes no processo de aprendizagem: "É o tipo de prática que estimula a gente a questionar e a estudar mais [...]. Acho que desperta a curiosidade e também te dá prazer de estudar [...]" (Estudante A, 2013). A troca de conhecimentos para além da sala de aula foi destacada por outra participante: "É uma oportunidade enorme de conhecer pessoas que estudam e atuam na área [...], essa participação é algo que eu valorizo até hoje, pois eu tenho a visão de que a troca de conhecimento é algo muito, mas muito importante não só pra mim como estudante, mas para mim como futura profissional de RP' (Estudante B, 2014). Além disso, 


\section{Atividades realizadas pelos estudantes no projeto Conexão}

\begin{tabular}{|l|l|}
\hline Motivar (-se) & $\begin{array}{l}\text { Conhecer um departamento de comunicação; } \\
\text { Apresentar o trabalho em um evento científico. }\end{array}$ \\
\hline Informar (-se) & $\begin{array}{l}\text { Estudar os conceitos de Relações Públicas; } \\
\text { Buscar informações sobre a organização real a ser estudada; } \\
\text { Realizar entrevistas com profissional de comunicação. }\end{array}$ \\
\hline Ativar (-se) & $\begin{array}{l}\text { Analisar as informações obtidas nas entrevistas a partir das teorias } \\
\text { estudadas; } \\
\text { Interpretar os resultados coletados utilizando matriz de análise conceitual; } \\
\text { Tirar conclusões. }\end{array}$ \\
\hline Feedbacks parciais; \\
\hline $\begin{array}{l}\text { Orientações frequentes; } \\
\text { Interação com profissionais de mercado, colegas do grupo e de outros } \\
\text { grupos e turmas, professores, pesquisadores e estudantes de diferentes } \\
\text { estados/países. }\end{array}$ \\
\hline Prteragir & $\begin{array}{l}\text { Produção de trabalho de cada grupo; } \\
\text { Produção de relatório único de todos os grupos para apresentação em } \\
\text { congresso. }\end{array}$ \\
\hline
\end{tabular}

Quadro 2 - Processo de aprendizagem versus atividades do projeto Conexão. Fonte: Autores deste texto.

o caráter científico e o potencial de integrar teoria e prática do projeto foram salientados por outra estudante: "[...] foi o primeiro Congresso, o primeiro evento acadêmico [...] foi importante a gente apresentar para professores [...] e pessoas de outros lugares [...]. Eu gostei muito da parte prática de ir na empresa. Acho que foi uma forma legal da gente começar o curso. Para ver como é na realidade [...]" (Estudante $\mathrm{C}, 2014)$.

Sob a óptica dos componentes de aprendizagem de Lebrun (2002), verificou-se que as principais dificuldades aconteceram nas fases "ativar (-se)" (analisar as informações) e "produzir" (criar o trabalho final coletivo), talvez por envolverem operações mais complexas do pensamento. Nessa etapa, a intervenção do docente deve ser mais pontual e intensa.

Além disso, com o objetivo de aumentar a autonomia do estudante no processo de aprendizagem, em trabalhos futuros, é possível convidá-los a discutir o roteiro e elaborar novos tópicos a se- rem incluídos no estudo. Os projetos produzidos a cada ano também servem como incentivo para as novas turmas que iniciam o curso. A utilização do ambiente virtual de aprendizagem e de recursos interativos, tais como os fóruns, pode ampliar a troca de conhecimentos entre os diferentes grupos que participam da atividade no decorrer do semestre. É possível ainda incluir momentos de avaliação pelos pares e autoavaliação dos projetos pelas próprias equipes, estimulando a reflexão e a crítica e aumentando o nível de engajamento dos estudantes no processo de aprendizagem (BIGGS, 1999).

\section{Conclusão}

Analisar as etapas do projeto Conexão com base nos componentes de aprendizagem de Lebrun (2002) tem contribuído para a melhoria do planejamento e da avaliação das atividades nas turmas seguintes. Foi marcante o envolvimento dos estudantes no projeto 
a partir do desafio de conhecer um departamento de comunicação e apresentar os resultados do trabalho da turma em um evento científico.

Sobre a forma como os estudantes lidam com a aprendizagem, confirmou-se que as estratégias educacionais ativas podem ampliar o nível de engajamento deles (BIGGS, 1999), sendo necessário conhecimento teórico, técnico e didático do docente, assim como o bom relacionamento com os estudantes e comprometimento com o processo de ensino-aprendizagem. Dessa forma, a formação e a valorização do professor da educação superior devem fazer parte do projeto pedagógico do curso e da cultura da instituição.

Vale destacar ainda que essa experiência ocorreu em um curso de graduação de Relações Públicas no âmbito de uma instituição de ensino superior pública; logo, é necessário cautela para a transposição didática dessa prática para outros contextos.

Enfim, o projeto teórico-prático chamado $\mathrm{Co}_{0}$ nexão, realizado na disciplina Teoria e História das Relações Públicas, pode ser considerado como a "ponta do iceberg", uma vez que muitas outras metodologias ativas devem ser incorporadas pelos docentes, tanto em sala de aula como fora do horário de classe. Ainda assim, é um exemplo de atividade didática que integra teoria e prática e pode contribuir para a reflexão de docentes e gestores de cursos preocupados com a melhoria dos processos educativos.

\section{Nota}

1 Uma primeira versão deste relato de experiência foi apresentada no $1^{\circ}$ Congresso de Graduação da Uni- versidade de São Paulo (2015) e no XVIII Encontro

Nacional de Didática e Prática de Ensino (2016).

\section{Referências Bibliográficas}

ALMEIDA, Maria Isabel; PIMENTA, Selma Garrido. "A Construção da Pedagogia Universitária no Âmbito da Universidade de São Paulo". In: PIMENTA, Selma Garrido \& ALMEIDA, Maria Isabel (orgs.). Pedagogia Universitária: Caminhos para a Formação de Professores. São Paulo: Cortez, 2011, pp. 19-43.

ANDRADE, Cândido Teobaldo de Souza. "O Ensino de Relações Públicas e as Exigências dos Novos Tempos". In: KUNSCH, Margarida M. Krohling (org.). Comunicaşão e Educaşão: Caminhos Cruzados. São Paulo: Edições Loyola, 1986, pp. 292-296.

BIGGS, John. "What the Student Does: Teaching for Enhanced Learning". Higher Education Research \& Development, vol. 18, n. 1, pp. 57-75, 1999.

BORDENAVE, Juan Díaz \& PEREIRA, Adair Martins. Estratégias de Ensino Aprendizagem. 5. ed. Petrópolis: Vozes, 1983.

BRAGA, José Luiz. "A Formação de Professores para a Comunicação". In: KUNSCH, M. M. K. (org.). $O$ Ensino de Comunicasãa: Análises, Tendências e Perspectivas Futuras. São Paulo: Abecom; ECA/USP, 1992.

BROPHY, Jere. "Synthesis of Researches on Strategies for Motivating Students to Learn". Education Leadership, 1987, pp. 40-48. Disponível em: <http://www. ascd.org/ASCD/pdf/journals/ed_lead/el_198710_brophy.pd† $>$. Acessado em 4 nov. 2015.

FERRARI, Maria Aparecida. Perfil dos Cursos de Relações Públicas no Brasil: uma Visão dos Coordenadores e Docentes do Processo Ensino-Aprendizagem. Tese (Livre-Docência), Escola de Comunicações e Artes da Universidade de São Paulo, 2017.

KNOWLES, Malcom S. The Modern Practice of Adult Education: from Pedagogy to Androgogy. New York: Cambridge, 1970 .

LEBRUN, Marcel. Teorias e Métodos Pedagógicos para Ensinar e Aprender. Lisboa: Instituto Piaget, 2002. 